\title{
Neck circumference in children and adolescents - an emerging tool for screening central obesity
}

\author{
M Malini ${ }^{1}$, S Kalpana ${ }^{2}$, S Lakshmi ${ }^{3}$ \\ From ${ }^{1}$ Junior Resident, ${ }^{3}$ Professor, Department of Pediatrics, Institute of Child Health and Hospital for Children, Chennai, Tamil Nadu, India, \\ ${ }^{2}$ Associate Professor, Department of Pediatrics, Government Vellore Medical College, Vellore, Tamil Nadu, India
}

\begin{abstract}
Objectives: The aim of the study was to validate the utility of neck circumference (NC) as an anthropometric measure of the central obesity and its correlation with body mass index (BMI) and waist circumference (WC). The aim of the study was to determine age and gender specific NC cutoffs for screening central obesity. Materials and Methods: This descriptive study was conducted in 1139 children and adolescents aged 6-17 years. NC, WC, and BMI were measured. To define overweight and obesity in children, the $23^{\text {rd }}$ and $27^{\text {th }}$ adult equivalent lines for BMI as presented in the revised Indian Academy of Pediatrics growth charts were used. Results: Overweight and obese children had significantly higher NC than those with normal BMI $(\mathrm{p}<0.001)$. NC showed a positive correlation with both WC and BMI ( $<0.001$ ). In children aged $<12$ years, NC cutoff for screening obesity was $26.5 \mathrm{~cm}$ in both boys (sensitivity $83.3 \%$ and specificity $71.7 \%$ ) and girls $(81.4 \%$ and $70.5 \%)$. The area under the curve for NC was greater than that of WC in both boys ( 0.86 vs. 0.76 ) and girls ( 0.82 vs. 0.66 ). In children aged $12-17$ years, $\mathrm{NC}$ cutoff values were $34 \mathrm{~cm}$ in boys (sensitivity $83.33 \%$ and specificity $75.60 \%$ ) and $31 \mathrm{~cm}$ in girls $(94.34 \%$ and $83.29 \%)$. The area under curve for WC was greater than that of NC in boys (0.94 vs. 0.88$)$ and almost similar in girls (0.96 vs. 0.95$)$. Conclusions: $\mathrm{NC}$ can accurately identify children with a high BMI. It is a better anthropometric measure than WC in identifying prepubertal children with central obesity. In children aged 12-17 years, it can be considered a good alternative for screening central obesity.
\end{abstract}

Key words: Body mass index, Neck circumference, Obesity

$\mathrm{W}$ orldwide, there has been a significant rise in the prevalence of obesity with over 340 million children and adolescents aged 5-19 years estimated to be either overweight or obese [1]. This corresponds to a more than four-fold increase in the combined prevalence of overweight and obesity from $4 \%$ in 1975 to over $18 \%$ in 2016. According to the World Health Organization (WHO), an estimated 38.2 million children under the age of 5 years were overweight or obese in 2019, almost half of whom lived in Asia [1]. A systematic review conducted by Ranjani et al. of 52 studies from 16 Indian states showed a rise in the combined prevalence of overweight and obesity in Indian children from $15.9 \%$ before 2001 to $19.3 \%$ in studies reported after 2010 [2]. This alarming global trend needs to be given due importance as childhood obesity has been related to an increase in mortality as evidenced by the Hoffman study which observed an almost two-fold increase in mortality in overweight adolescents during a 20 year follow-up [3].

\section{Access this article online}

Received - 17 December 2021

Initial Review - 19 January 2022

Accepted - 21 January 2022

DOI: $10.32677 /$ ijch.v9i1.3299
At present, there are several indicators of obesity in practice such as body mass index (BMI), waist circumference (WC), and waist-hip ratio, but each tool has its own limitations. Conventionally, BMI has been employed as a measure of the central adiposity but it does not differentiate between lean mass and fat mass. It also does not take into account body fat distribution [4]. This is of utmost significance, as the central adiposity, particularly high levels of upper-body visceral fat, is a better predictor of cardiovascular events than generalized adiposity [5]. Although WC is a frequently used anthropometric measure of obesity, it does not account for differences in height, and therefore, potentially over-and under-evaluates risk for tall and short individuals, respectively [6]. It also needs to be adjusted for timing of the last meal and clothing which can be cumbersome when used for screening purposes especially in adolescents and in large population-based studies.

Recent studies have shown neck circumference (NC) to be a reliable and practical anthropometric measurement to assess upper body adiposity which is known to correlate with visceral adiposity and thereby predict cardiometabolic risk $[7,8]$. The

Correspondence to: S Kalpana, No.1, $2^{\text {nd }}$ Cross Street, $3^{\text {rd }}$ Main Road, Nolambur Phase 1, Chennai - 600 037, Tamil Nadu, India. E-mail: drskalpana@yahoo.co.in

(C) 2022 Creative Commons Attribution-NonCommercial 4.0 International License (CC BY-NC-ND 4.0). 
renowned Framingham heart study reported that $\mathrm{NC}$ is an index of central obesity as it associates independently with visceral adiposity and BMI [9]. However, there are only a few studies that provide reference data on $\mathrm{NC}$ measurements worldwide [1012]. There is a paucity of nationwide studies regarding the utility of $\mathrm{NC}$ in screening obesity in the Indian pediatric population $[13,14]$. This study was done to validate the usefulness of $\mathrm{NC}$ as an anthropometric measure of central obesity and its correlation with BMI and WC. We also determined NC cutoffs for screening central obesity in Indian children.

\section{MATERIALS AND METHODS}

This descriptive study was conducted in six schools (government and private) in Chennai from September 2017 to September 2018 and included children and adolescents aged 6-17 years. We calculated that a study population of 1048 children would be adequate to provide a statistical power of $90 \%$ to detect a significant correlation between $\mathrm{NC}$ and $\mathrm{BMI}$, at a significance level of 5\%, considering the sample correlation coefficient $(\mathrm{r})$ as 0.61 , which is the least among the many correlation coefficients reported in the literature for $\mathrm{BMI}$ and $\mathrm{NC}$ and assuming the population correlation coefficient to be 0.55 . It was decided to divide the study population into two clusters of 6-11 years and 12-17 years. Institutional Ethics Committee clearance was obtained and 1139 children were then enrolled by systematic random sampling using the students list in the attendance register in each class. Only healthy children were included in the study. Children with goiter, swellings, or cysts in the neck, abnormalities of the cervical spine such as craniovertebral junction anomalies, acute, and chronic medical disorders and those on exogenous steroids were excluded from the study.

Anthropometric data of students, including height, weight, $\mathrm{NC}$, and $\mathrm{WC}$ were recorded by a single investigator eliminating inter-observer bias. The average of two measurements was taken to minimize intra-observer bias. Children were examined without shoes or extra clothing other than their school uniform for body weight measurement. The electronic weighing scale was used and was corrected for any zero error before measurement. Height was measured using a stadiometer, with the children standing upright, arms held by their side and head looking forwards, positioned such that the Frankfurt plane was parallel to the floor. Weight and height were measured using scales with an accuracy of $0.1 \mathrm{~kg}$ and $0.1 \mathrm{~cm}$, respectively.
$\mathrm{NC}$ was measured using a non-stretchable plastic tape at the level of the thyroid cartilage, immediately below the laryngeal prominence, with the child standing and looking straight ahead with the shoulders relaxed [15]. WC was measured with the child standing straight, at the midpoint between the costal margin and the upper edge of the iliac crest, at the end of normal expiration. BMI percentiles were determined for each individual using revised Indian Academy of Pediatrics (IAP) growth charts. To define underweight, overweight and obesity in children, the $3^{\text {rd }}, 23^{\text {rd }}$, and $27^{\text {th }}$ adult equivalent lines for BMI as presented in the revised IAP growth charts, were used. Statistical analysis was performed using Statistical Package for the Social Science version 24.0. All categorical parameters were summarized using frequency and percentages. All continuous measurements were presented as Mean \pm Standard Deviation. The cutoff values for NC and WC in school going children and adolescents were determined by Youden index. Receiver operating characteristic (ROC) analysis was done to find the optimal sensitivity and specificity for $\mathrm{NC}$ and WC against BMI. Means of clinical parameters were compared between different BMI categories using analysis of variance. $\mathrm{P}<0.05$ was considered statistically significant.

\section{RESULTS}

Our study included 1139 children of whom 515 (45.22\%) were boys and $624(54.78 \%)$ were girls; $242(21.2 \%)$ children belonged to the $<12$ year age group and $897(78.7 \%)$ belonged to $12-17$ year category. Seventy-three $(6.4 \%)$ were underweight, $750(65.8 \%)$ were normal, $176(15.4 \%)$ were overweight, and $140(12.3 \%)$ were obese. Data regarding the mean values of study variables such as age, weight, height, $\mathrm{NC}, \mathrm{WC}$, and $\mathrm{BMI}$ across the study population are shown in Table 1.

The mean NC across the study population in children with a normal BMI was $30 \pm 3.38 \mathrm{~cm}$ in boys and $27.8 \pm 2.39 \mathrm{~cm}$ in girls. In overweight children, it was $33.1 \pm 2.90 \mathrm{~cm}$ in boys and $30.1 \pm 2.25 \mathrm{~cm}$ in girls. In obese children, it was $34 \pm 4.51 \mathrm{~cm}$ in boys and $31.7 \pm 3.44 \mathrm{~cm}$ in girls. NC was significantly higher in overweight and obese children compared to those with a normal BMI in both genders $(\mathrm{p}<0.001)$.

In children aged $<12$ years, there was a positive correlation between NC and BMI; $(r=0.84$ in boys $[p<0.001]$ and $r=0.75$ in girls $[\mathrm{p}<0.001])$. We also observed a positive correlation between $\mathrm{NC}$ and $\mathrm{WC}(\mathrm{r}=0.87$ in boys $[\mathrm{p}<0.001]$ and $\mathrm{r}=0.84$ in girls

Table 1: Demographic and baseline characteristics of study population

\begin{tabular}{|c|c|c|c|c|c|}
\hline \multirow[t]{2}{*}{ Parameters } & \multicolumn{2}{|c|}{$<12$ Years } & \multicolumn{2}{|c|}{$>=12$ Years } & \multirow[t]{2}{*}{ Overall $(n=1139)$} \\
\hline & Boys $(n=96)$ & Girls $(n=146)$ & Boys $(n=419)$ & Girls $(n=478)$ & \\
\hline Age (y) & $8.58 \pm 1.93$ & $9.6 \pm 1.89$ & $15.34 \pm 1.72$ & $14.94 \pm 1.83$ & $13.87 \pm 3.04$ \\
\hline Weight (kg) & $25.86 \pm 10.06$ & $29.21 \pm 9.87$ & $51.09 \pm 14.78$ & $46.85 \pm 12.22$ & $44.38 \pm 15.53$ \\
\hline Height $(\mathrm{cm})$ & $126.3 \pm 12.11$ & $131.0 \pm 13.67$ & $162.4 \pm 11.04$ & $152.79 \pm 7.46$ & $151.33 \pm 16$ \\
\hline $\mathrm{NC}(\mathrm{cm})$ & $25.95 \pm 2.37$ & $25.88 \pm 2.2$ & $31.93 \pm 3.29$ & $29.49 \pm 2.62$ & $29.63 \pm 3.58$ \\
\hline $\mathrm{WC}(\mathrm{cm})$ & $53.53 \pm 9.44$ & $54.65 \pm 8.6$ & $68.92 \pm 11.36$ & $65.78 \pm 10.01$ & $64.48 \pm 11.69$ \\
\hline BMI $\left(\mathrm{kg} / \mathrm{m}^{2}\right)$ & $15.74 \pm 3.78$ & $16.65 \pm 3.68$ & $19.15 \pm 4.37$ & $19.93 \pm 4.42$ & $18.87 \pm 4.48$ \\
\hline
\end{tabular}

Continuous variables are shown as Mean \pm Standard deviation, NC: Neck circumference, WC: Waist circumference, BMI Body mass index 
$[p<0.001])$. Furthermore, in the $12-17$ year category, NC and BMI had a positive correlation $(r=0.73$ in boys $[p<0.001]$ and $r=0.84$ in girls $[\mathrm{p}<0.001])$. Similarly, there was a positive correlation between $\mathrm{NC}$ and $\mathrm{WC}$ also $(\mathrm{r}=0.79$ in boys $[\mathrm{p}<0.001]$ and $\mathrm{r}=0.82$ in girls $[\mathrm{p}<0.001])$. The cutoff value of NC for screening obesity in boys aged 6-11 years was $26.5 \mathrm{~cm}$ with a sensitivity of $83.3 \%$ and specificity of $71.7 \%$. The cutoff value of WC was $54 \mathrm{~cm}$ with a sensitivity of $77.7 \%$ and specificity of $67.9 \%$. ROC curve analysis showed an area under the curve (AUC) of 0.86 for NC and 0.76 for WC (Fig. 1). In girls aged 6-11 years, the cutoff value of $\mathrm{NC}$ for screening obesity was $26.5 \mathrm{~cm}$ with a sensitivity of $81.4 \%$ and specificity of $70.5 \%$. The cutoff value of WC was $52.5 \mathrm{~cm}$ with a sensitivity of $62.9 \%$ and specificity of $52.1 \%$. We observed an AUC of 0.82 for NC and 0.67 for WC (Fig. 2).

The cutoff value of $\mathrm{NC}$ for screening obesity in boys aged $12-17$ years was $34 \mathrm{~cm}$ with a sensitivity of $83.3 \%$ and specificity of $75.6 \%$. The cutoff value of WC was $79 \mathrm{~cm}$ with a sensitivity of $88 \%$ and specificity of $88.5 \%$. ROC curve analysis showed an AUC of 0.88 for $\mathrm{NC}$ and 0.94 for WC (Fig. 3). In girls aged 12-17 years, the cutoff value of NC was $31 \mathrm{~cm}$ with a sensitivity

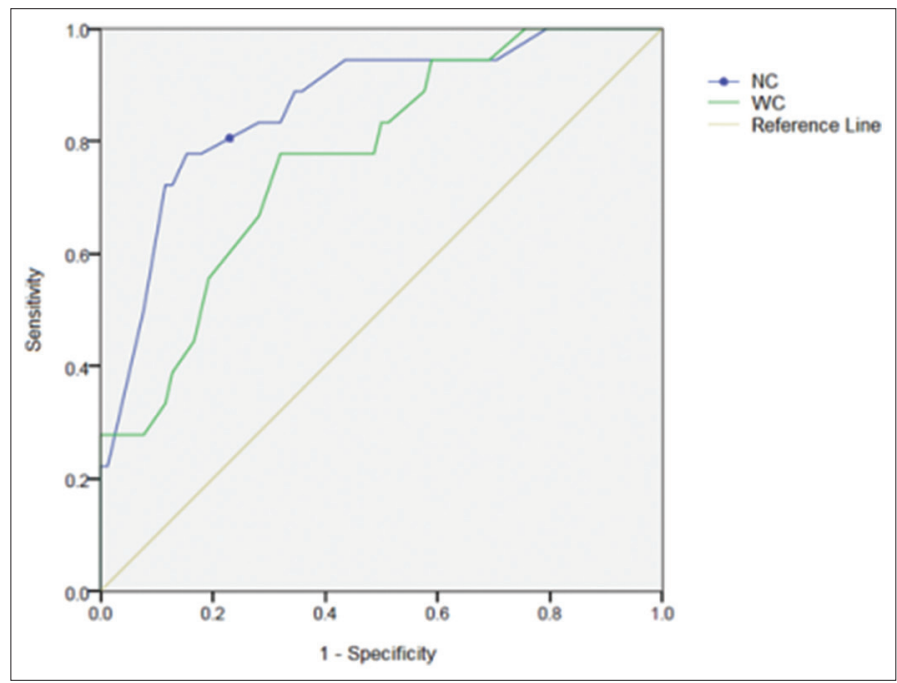

Figure 1: Receiver operating characteristic curve comparing neck circumference and waist circumference in boys $<12$ years

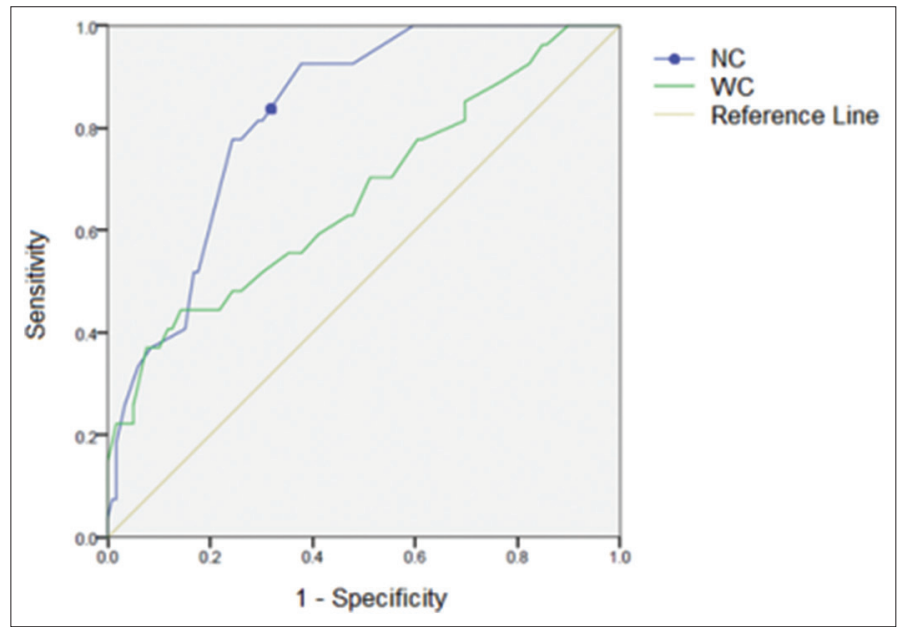

Figure 2: Receiver operating characteristic curve comparing neck circumference and waist circumference in girls aged $<12$ years of $94.3 \%$ and specificity of $83.2 \%$. The cutoff value of WC was $74 \mathrm{~cm}$ with a sensitivity of $96.2 \%$ and specificity of $89.4 \%$. We observed an AUC of 0.95 for NC and 0.96 for WC (Fig. 4).

\section{DISCUSSION}

$\mathrm{NC}$ is an emerging tool for the assessment of the central obesity. However, its use in the pediatric population is currently limited due to the lack of reference data. In this study, we assessed the utility of $\mathrm{NC}$ and determined cutoffs for detecting central obesity in children.

$\mathrm{NC}$ values increase with age as children grow. The studies have demonstrated dynamic changes in the regional distribution of body fat during puberty in both genders [16]. The average age of puberty is 12 years in boys and 11 years in girls [17,18]. Growth acceleration occurs during Tanner Stage 3 of breast development in girls and Tanner Stage 4 of pubic hair development in boys [18]. Hence, factoring in these changes in adiposity, we stratified our study population into two age groups. The mean $\mathrm{NC}$ values were almost similar in children of both genders in the $<12$ year category.

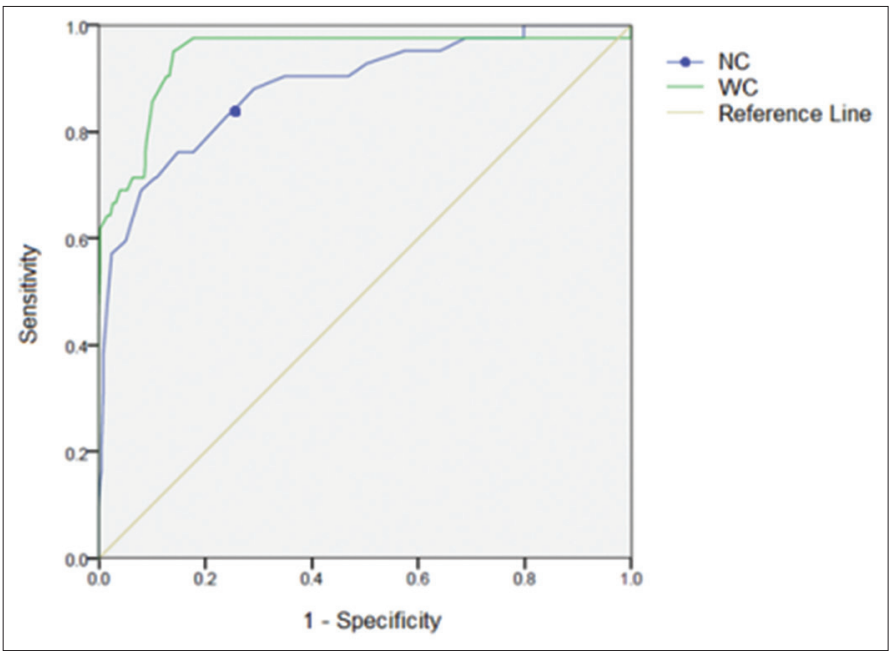

Figure 3: Receiver operating characteristic curve comparing neck circumference and waist circumference in boys aged 12-17 years

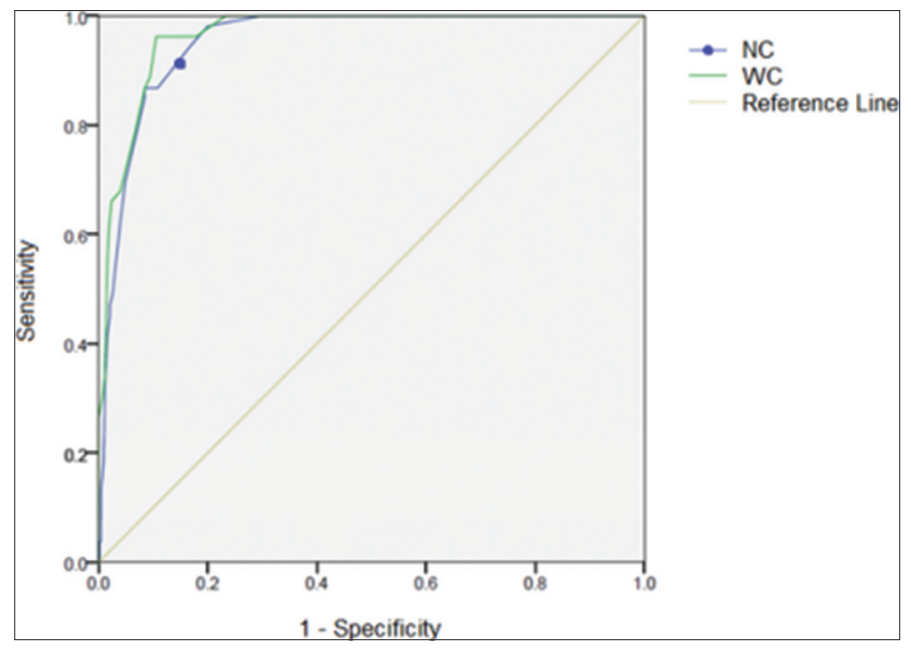

Figure 4: Receiver operating characteristic curve comparing neck circumference and waist circumference in girls aged 12-17 years 
This was further corroborated by a similar NC cutoff of $26.5 \mathrm{~cm}$ for screening obesity in both boys and girls. However, there was a significant difference of $2.44 \mathrm{~cm}$ in the mean NC between boys and girls in the $12-17$ year category $(\mathrm{p}<0.0001)$.

Similar observations were made by Kondolot et al. [10] and Nagy et al. [11], who recorded higher NC values in boys. This can be attributed to the differences in regional distribution of fat mass and lean mass between men and women, beginning at puberty [19]. Studies in the adult population have reported a greater overall volume of soft tissue in the neck in males when analyzed both segmentally and as a whole [20].

Children and adolescents who were categorized as overweight and obese had significantly higher $\mathrm{NC}$ values than children with normal BMI for both genders $(\mathrm{p}<0.001)$. Furthermore, there was a positive correlation of $\mathrm{NC}$ with $\mathrm{WC}$ and $\mathrm{BMI}$ in both genders across all age groups. $\mathrm{NC}$ had good diagnostic accuracy to detect obesity, with AUC values ranging from 0.86 to 0.95 across the study population. Similar observations were reported in two other studies in Indian adolescents by Patnaik et al. [13] in Eastern India and Yashoda et al. in Bangalore [14].

The cutoff values of $\mathrm{NC}$ obtained in our study for screening obesity $(34 \mathrm{~cm}$ in boys and $31 \mathrm{~cm}$ in girls aged $12-17$ years; $26.5 \mathrm{~cm}$ in children $<12$ years) were close to the estimates mentioned in the World literature $[10,11,12]$ and Indian literature [13,14]. NC cutoff values in adolescents reported by Yashoda et al. were $32 \mathrm{~cm}$ in boys and $30 \mathrm{~cm}$ in girls with a sensitivity of $81.8 \%$ and $84.8 \%$, respectively, while in the study by Patnaik et al., it was $30.75 \mathrm{~cm}$ in boys and $29.75 \mathrm{~cm}$ in girls with a sensitivity of $79.2 \%$ and $72.5 \%$, respectively. The minimal variations observed among different studies can probably be explained by differences in race and ethnicity of the study population. Moreover, the age group of the study population also varied among different studies.

In children aged $<12$ years, NC performed better than WC as a screening tool for detecting central obesity in both boys and girls. To the best of our knowledge, there are no Indian studies evaluating $\mathrm{NC}$ as a screening tool for obesity in prepubertal children. Even in children aged 12-17 years, NC performed as well as WC in girls in detecting obesity; in boys, it had sensitivity comparable to WC. Hence, NC can be considered a reliable alternative to $\mathrm{WC}$ for screening central obesity in children aged 6-17 years. In fact, few recent studies have shown $\mathrm{NC}$ to have a similar or better association than WC with metabolic parameters which predict cardiovascular risk $[7,8]$.

$\mathrm{NC}$ was better associated with computed-tomography measured visceral adipose tissue than WC, probably due to the drawback of subcutaneous fat contributing to WC measurement $[21,22]$. NC also did not require adjustment for height, as the associations were similar even when variations in height were considered using neck to height ratio [23]. Finally, measurement of WC can be cumbersome especially in adolescents as it needs to be adjusted for clothing and timing of the last meal. This can cause constraints on its use in large and population-based studies.

However, our study had certain limitations. Children more than 12 years of age contributed to $75 \%$ of the study population.
This was due to the fact that the number of children enrolled in these schools in the 6-11 years age group was considerably less in number. Hence, this limited the analysis and stratification of the results by age. Sexual maturity rating of children could not be assessed due to ethical and practical reasons. Geographical limitations due to lack of representation from rural areas also need to be considered. In our study, the utility of $\mathrm{NC}$ as a screening tool for detecting obesity was evaluated with BMI as the standard criteria rather than with methods such as dual-energy X-ray absorptiometry and air displacement plethysmography which analyze body composition and thereby measure body fat percentage.

\section{CONCLUSIONS}

$\mathrm{NC}$ is a better anthropometric measure than $\mathrm{WC}$ to screen for central obesity in children aged 6-11 years. In children aged 12-17 years, NC has sensitivity comparable to WC, albeit slightly lower. Hence, $\mathrm{NC}$ can be considered as a good alternative screening tool for identifying central obesity in children aged $6-17$ years [24].

\section{REFERENCES}

1. World Health Organisation. Obesity and Overweight. Geneva: World Health Organisation; 2020. Available from: https://www.who.int/news-room/factsheets/detail/obesity-and-overweight [Last accessed on $2020 \mathrm{Jul} 15]$.

2. Ranjani H, Mehreen TS, Pradeepa R, Anjana RM, Garg R, Anand K, et al. Epidemiology of childhood overweight and obesity in India: A systematic review. Indian J Med Res 2016;143:160-74.

3. Hoffmans MD, Kromhout D, de Lezenne Coulander C. The impact of body mass index of 78, 612, 18-year old Dutch men on 32-year mortality from all causes. J Clin Epidemiol 1988;41:749-56.

4. Jackson AS, Stanforth PR, Gagnon J, Rankinen T, Leon AS, Rao DC, et al. The effect of sex, age and race on estimating percentage body fat from body mass index: The Heritage Family Study. Int J Obes Relat Metab Disord 2002;26:789-96.

5. Cornier MA, Despres JP, Davis N, Grossniklaus DA, Klein S, Lamarche B, et al. Assessing adiposity: A scientific statement from the American Heart Association. Circulation 2011;124:1996-2019.

6. Browning LM, Hsieh SD, Ashwell M. A systematic review of waist-toheight ratio as a screening tool for the prediction of cardiovascular disease and diabetes: 0.5 could be a suitable global boundary value. Nutr Res Rev 2010;23:247-69.

7. Onat A, Hergenç G, Yuksel H, Can G, Ayhan E, Kaya Z, et al. Neck circumference as a measure of central obesity: Associations with metabolic syndrome and obstructive sleep apnea syndrome beyond waist circumference. Clin Nutr 2009;28:46-51.

8. Preis SR, Massaro J, Hoffmann U, D’Agostino RB Sr., Levy D, Robins SJ, et al. Neck Circumference as a novel measure of cardiometabolic risk: The Framingham heart study. J Clin Endocrinol Metab 2010;95:3701-10.

9. Mahmood SS, Levy D, Vasan RS, Wang TJ. The Framingham Heart Study and the epidemiology of cardiovascular disease: A historical perspective. Lancet 2014;383:999-1008.

10. Kondolot M, Horoz D, Poyrazoğlu S, Borlu A, Öztürk A, Kurtoğlu S, et al. Neck circumference to assess obesity in preschool children. J Clin Res Pediatr Endocrinol 2017;9:17-23.

11. Nagy P, Kovacs E, Moreno LA, Veidebaum T, Tornaritis M, Kourides Y, et al. Percentile reference values for anthropometric body composition indices in European children from the IDEFICS study. Int J Obes (Lond) 2014;38 Suppl 2:15-25.

12. Taheri M, Kajbaf TZ, Taheri MR, Aminzadeh M. Neck circumference as a useful marker for screening overweight and obesity in children and adolescents. Oman Med J 2016;31:170. 
13. Patnaik L, Pattnaik S, Rao EV, Sahu T. Validating neck circumference and waist circumference as anthropometric measures of overweight/obesity in adolescents. Indian Pediatr 2017;54:377-80.

14. Yashoda HT, Swetha B, Goutham AS. Neck circumference measurement as a screening tool for obesity in children. Int J Contemp Pediatr 2017;4:426-30.

15. Nafiu OO, Burke C, Lee J, Voepel-Lewis T, Malviya S, Tremper KK. Neck circumference as a screening measure for identifying children with high body mass index. Pediatrics 2010;126:e306-10.

16. Hillman JB, Biro FM. Dynamic changes of adiposity during puberty: Life may not be linear. J Adolesc Health 2010;47:322-3.

17. National Health Service. Stages of Puberty: What Happens to Boys and Girls; 2018. Available from: https://www.nhs.uk/live-well/sexual-health [Last accessed on 2019 Jun 10].

18. Garibaldi LR, Chemaitilly W. Disorders of pubertal development. In: Kliegman RM, Geme JS, Blum N, Shah SS, Tasker RC, editors. Nelson Textbook of Paediatrics. $21^{\text {st }}$ ed. Philadelphia, PA: Elsevier Health Sciences; 2020.

19. Simpson L, Mukherjee S, Cooper MN, Ward KL, Lee JD, Fedson AC, et al. Sex differences in the association of regional fat distribution with the severity of obstructive sleep apnea. Sleep 2010;33:467-74.

20. Whittle AT, Marshall I, Mortimore IL, Wraith PK, Sellar RJ, Douglas NJ. Neck soft tissue and fat distribution: Comparison between normal men and women by magnetic resonance imaging. Thorax 1999;54:323-8.

21. Li HX, Zhang F, Zhao D, Xin Z, Guo SQ, Wang SM, et al. Neck circumference as a measure of neck fat and abdominal visceral fat in Chinese adults. BMC Public Health 2014;14:1-7.

22. Assyov Y, Gateva A, Tsakova A, Kamenov Z. A comparison of the clinical usefulness of neck circumference and waist circumference in individuals with severe obesity. Endocr Res 2017;42:6-14.

23. Joshipura K, Muñoz-Torres F, Vergara J, Palacios C, Pérez CM. Neck circumference may be a better alternative to standard anthropometric measures. J Diabetes Res 2016;2016:6058916.

24. Valencia-Sosa E, Chávez-Palencia C, Romero-Velarde E, Larrosa-Haro A, Vásquez-Garibay EM, Ramos-García CO. Neck circumference as an indicator of elevated central adiposity in children. Public Health Nutr 2019;22:1755-61.

Funding: None; Conflicts of Interest: None Stated.

How to cite this article: Malini M, Kalpana S, Lakshmi S. Neck circumference in children and adolescents - an emerging tool for screening central obesity. Indian J Child Health. 2022; 9(1):11-15. 